\title{
The post-myocardial infarction scarred ventricle and congestive heart failure: The preeminence of magnetic resonance imaging for preoperative, intraoperative, and postoperative assessment
}

Vincent Dor, MD, Filippo Civaia, MD, Clara Alexandrescu, MD, and Françoise Montiglio, MD

An operative procedure can be precise and perfect only if it is based upon the surgeon's profound knowledge of anatomy, his understanding of the alteration of this normal anatomy by the pathology with which he is dealing and his ability to use the anatomic information in organizing and affecting his surgical procedure.

J. W. Kirklin ${ }^{1}$

Magnetic resonance imaging (MRI), with its ability to precisely define myocardial anatomy, echoes the teachings of one of cardiac surgery's most distinguished pioneers. Since the 1990s, several studies have demonstrated the preeminence of cardiac magnetic resonance (CMR) for analysis of wall motion abnormalities after myocardial infarction (MI). ${ }^{2,3}$ Both cine-MRI to determine precise scar location and the late enhancement technique to assess the transmural extension of infarcted myocardium illustrate the utility of CMR. CMR is the preeminent method of assessing left ventricular remodeling and aneurysmal progression after MI. Moreover, thrombus formation; the site, depth, and extension of the scarred myocardial wall; precise localization of asynergic areas; disorganization of the mitral apparatus; and estimation of left ventricular volume and performance are all circumstances in which CMR has proved more accurate than other techniques. ${ }^{4}$ In our opinion, a complete MRI evaluation of cardiac function is paramount before deciding how to appropriately treat patients after MI.

The core problem with ischemic congestive heart failure $(\mathrm{CHF})$ is the undue demand put on the residual viable left ventricular myocardium. As noted by Klein and colleagues ${ }^{5}$ more than 40 years ago, "When the myocardium in the aneurismal area functions improperly, or has been replaced by fibrosis in $20 \%-25 \%$ of the surface area of the left ventricle, the extent of shortening required of the remaining functioning heart begins to exceed physiological limits.', This was later confirmed by McKay and associates, ${ }^{6}$ who showed that left ventricular dilatation occurs when the asynergic (dyskinetic or akinetic) left ventricular circumference exceeds $40 \%$.

\footnotetext{
From the Centre Cardio-Thoracique de Monaco, Monte Carlo, Monaco. Received for publication April 22, 2008; accepted for publication July 31, 2008. Address for reprints: Vincent Dor, MD, Centre Cardio-Thoracique de Monaco, 11 bis, Avenue d'Ostende, Cedex MC 98004, Monte Carlo, Monaco (E-mail: vdor@ccm. $\mathrm{mc})$.

J Thorac Cardiovasc Surg 2008;136:1405-12

$0022-5223 / \$ 34.00$

Copyright (C) 2008 by The American Association for Thoracic Surgery

doi:10.1016/j.jtcvs.2008.07.044
}

MRI can be used as a complementary tool in the surgical care of post-MI ventricular dysfunction and the ischemic $\mathrm{CHF}$ that may ensue. What follows is concise summary of MRI's applicability to surgical care to treat this complex disease process.

\section{POSTISCHEMIC MYOCARDIAL ASSESSMENT}

Immediately after MI, MRI shows no reflow to the endocardium. ${ }^{7,8}$ This can be helpful, because it aids in predicting the degree of benefit to be expected from successful recanalization. Indeed, in patients seen many hours after coronary occlusion, demonstration by MRI of total lack of transmural reflow is highly suggestive that there is little in the way of viable tissue and that further intervention to reperfuse the myocardium is unlikely to improve on the residual impairment that remains. ${ }^{9}$ In addition, 5 to 15 days after $\mathrm{MI}$, CMR again becomes useful in the decision-making process, providing additional information about the scarred ventricle and its potential consequences.

To calculate reliable values of end-systolic volume index (ESVI), end-diastolic volume index (EDVI), and left ventricular ejection fraction (LVEF) true volumes of multiple parallel disks are added together. An increase of $20 \%$ in EDVI is considered to be the definition of left ventricular remodelling, ${ }^{10}$ and an ESVI greater than $60 \mathrm{~mL} / \mathrm{m}^{2}$ is a criterion for chronic advanced heart failure. ${ }^{11}$

The site, depth, and extension of the scarred wall may be evaluated completely with 4 MRI projections. The 2-chamber view is used to assess the anterior and posterior walls of the left ventricle, the 4-chamber view allows assessment of the septum and lateral wall, the short-axis view enables a staged analysis of the septum and papillary muscles, and the projection that illustrates the left ventricular outflow tract (accordingly entitled the left ventricular outflow tract view) also provides a detailed analysis of the mitral apparatus (Figure 1).

The silhouette of an asynergic left ventricle cannot be correctly characterized by a simple plane angiogram in the right oblique projection, because this view cannot "see" the septum and lateral wall. The classification of left ventricular aneurysms into four types by means of this technique is thus obsolete. The type of asynergy is often correlated with the depth of the scar, being dyskinesia when the scar is transmural and akinesia when the scar is subendocardial (Figure 2). ${ }^{12}$

The extension of wall motion abnormality was for decades analyzed by the center-line method, which is still 


$$
\begin{aligned}
& \text { Abbreviations and Acronyms } \\
& \begin{aligned}
\text { CHF } & =\text { congestive heart failure } \\
\text { CMR } & =\text { cardiac magnetic resonance } \\
\text { DVBS } & =\text { diastolic volume balloon sizing } \\
\text { EDVI } & =\text { end-diastolic volume index } \\
\text { ESVI } & =\text { end-systolic volume index } \\
\text { EVCPP } & =\text { endoventricular circular patch plasty } \\
\text { IFV } & =\text { ischemic failing ventricle } \\
\text { LVEF } & =\text { left ventricular ejection fraction } \\
\text { LVR } & =\text { left ventricular reconstruction } \\
\text { MI } & =\text { myocardial infarction } \\
\text { MRI } & =\text { magnetic resonance imaging } \\
\text { SI } & =\text { sphericity index }
\end{aligned}
\end{aligned}
$$

used, but limited to the right oblique projection. ${ }^{13}$ The gadolinium injected during MRI is especially fixed on dead tissue, outlining the limit of irreversibly scarred myocardium. ${ }^{14}$ The ratio between scar length (by late gadolinium enhancement [LGE]) and length of the left ventricular circumference gives a result similar to the center-line method, but this result can be analyzed with the 4 projections, allowing a more precise estimation of the percentage of asynergic wall. LGE is helpful in verifying the percentage of remaining contractile myocardium on the anterior, lateral, and septal walls, allowing the surgeon to learn whether the endoventricular reconstruction is feasible and how it can be carried out inside the ventricle.

The analysis of mitral valve anatomy and dysfunction can be fully assessed by CMR. The presence of mitral regurgita- tion, coaptation of leaflets, diameter of the annulus, distance between the papillary muscles (analyzed at the level of the tips), and the distance between basal interpapillary muscles are all accurately evaluated with CMR. In the case of left ventricular dilatation, the tips of the papillary muscles are often increased. Conversely, for both anteroseptoapical and posterior aneurysms, even when extremely large, the interpapillary muscles are never affected. Only posterolateral aneurysms related to occlusion of the obtuse marginal (less than $5 \%$ of cases) result in distention of the interpapillary muscles. In practice, however, infarction from obtuse marginal occlusion is more often complicated by limited free-wall rupture or papillary muscle rupture than is a lateral wall aneurysm.

This absence of involvement of the papillary muscle in anteroseptoapical aneurysms and most posterior or posteroseptal aneurysms is explained by pathoanatomy. ${ }^{15}$ The papillary muscles are not inserted onto the septum. Instead, the anterior papillary muscle is inserted on the lateral wall and the posterior papillary muscle onto the posterolateral wall (Figure 3). As illustrated by McAlpine ${ }^{16}$ and well known to anatomic pathologists, the orifice of an anteroseptal aneurysm is septoapical, because the septum is more affected than the anterior wall during an obstruction of the left anterior descending artery. The orifice of the posterior aneurysm is also posteroseptal. The basal papillary muscle can be remote from the septum, but the interpapillary muscle remains stable (Figure 4). Consequently, the diagram often used to explain mitral insufficiency complicating left ventricular remodeling by distention between septal and lateral papillary muscles does not correspond to normal anatomy or to pathoanatomy. In reality, for an anteroseptoapical aneurysm,

\section{SILHOUETTES DEPEND ON SCAR LOCALIZATIONS}

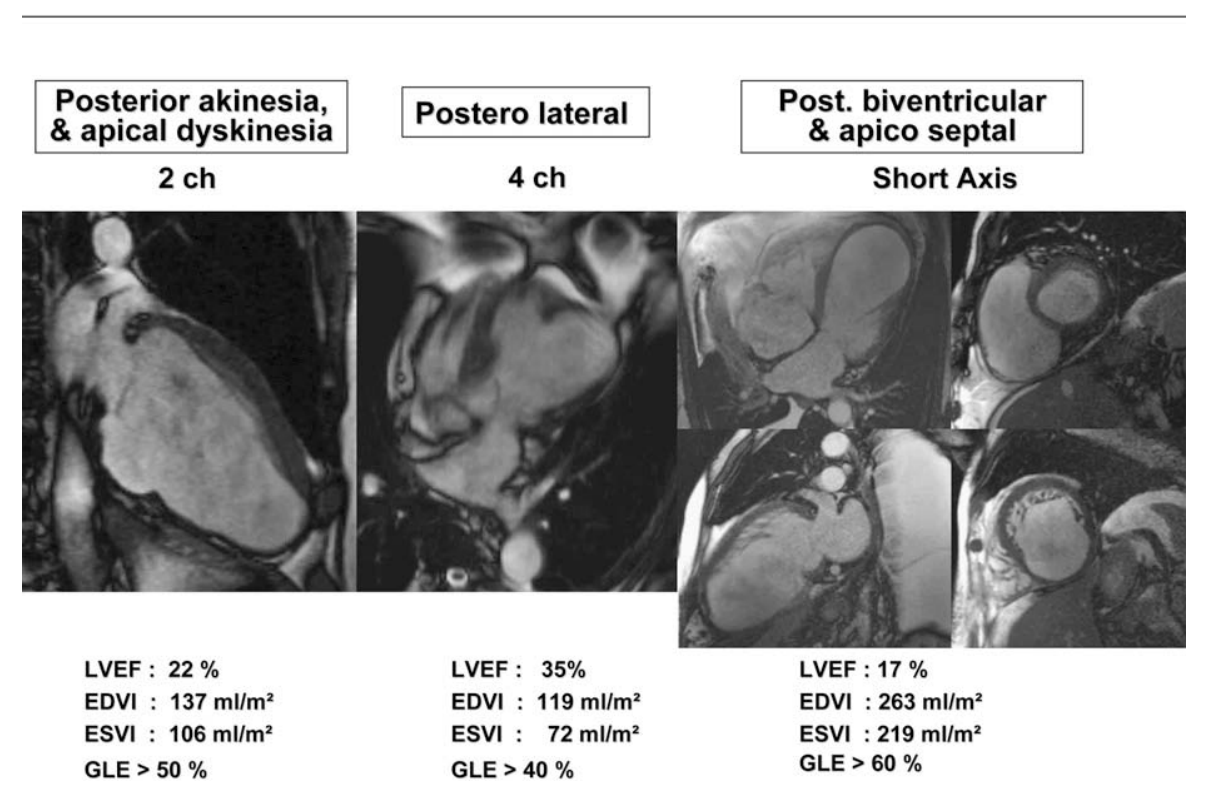

FIGURE 1. Analysis of 2-chamber and short-axes views showing exactly localization of wall motion abnormality. 
TYPE OF ASYNERGY (dyskinesia, akinesia) depends on depth's scar
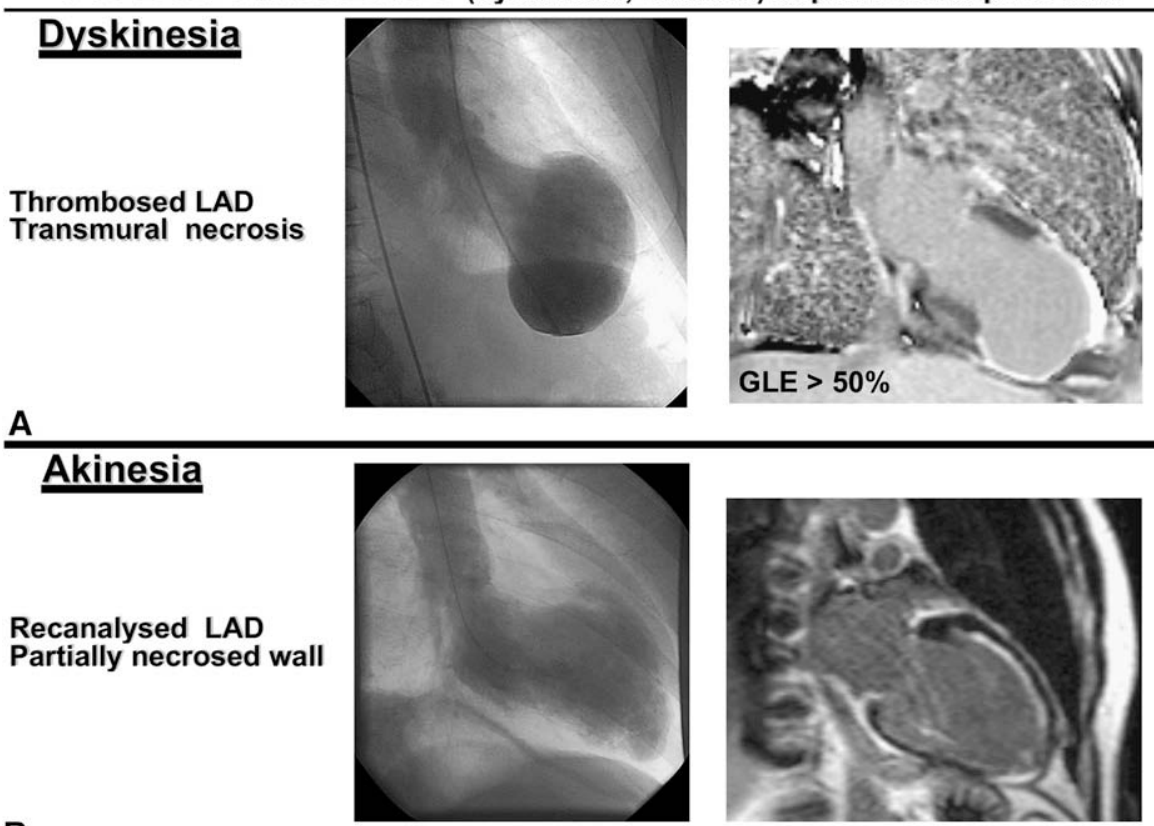

B

FIGURE 2. Magnetic resonance imaging showing depth of left ventricular scar: transmural (A) and subendocardial (B).

mitral regurgitation is always connected with annular dilatation and is well corrected by a posterior annuloplasty. Only preexisting degenerative disease or concomitant involvement of the mitral apparatus can lead to chordal or papillary muscle repair.

\section{MRI AND SURGICAL LEFT VENTRICULAR RECONSTRUCTION}

The cause of left ventricular remodeling after MI is the scarred left ventricular wall. With this in mind, the goal of surgical treatment is to suppress or exclude the scarred portion of the ventricle from the adjacent viable myocardium. Left ventricular reconstruction (LVR) by endoventricular circular patch plasty (EVCPP) has proved a successful option to accomplish this task. ${ }^{17,18}$ The underlying principle behind EVCPP is attainment of complete circular reorganization (from inside the left ventricular cavity to allow complete epicardial coronary revascularization) of the contractile myocardium by a continuous suture, positioned between normal and scarred myocardium, in an effort to restructure the curvature of the left ventricular wall back to its original geometric configuration, as it was before the MI (Figure 5, $A$ and $B$ ).

In most cases, asynergic areas cannot be resected because they affect the septum and posterior wall. The endoventricular suture must follow the "contractility trail" outlined by the limit of the endocardial scar (Figure 6). When the endocardial scar is not well defined, it is of great interest to know the exact percentage of asynergy, which has to be excluded from each wall. This is accomplished with clarity by LGE cartography.
By 1998, after 14 years of experience with EVCPP reconstruction, despite promising immediate improvements in systolic function, more long-term follow-up made it apparent that disappointing secondary results of progressively impaired diastolic function and restrictive cardiomyopathic processes as a result of excess volume reduction necessitated technique modification. The technique has since been improved by the inclusion of diastolic volume balloon sizing (DVBS) to the surgical procedure. ${ }^{19,20}$ After positioning of the endoventricular suture, a rubber balloon is inflated inside the remaining left ventricular cavity at the theoretic diastolic volume of the patient $\left(50-60 \mathrm{~mL} / \mathrm{m}^{2}\right.$ body surface area). The suture is tied, and the balloon is deflated and removed. The shape and size of the patch to close the left ventricular cavity are determined by the remaining orifice (Figure 5, $C$ and $D$ ). The DVBS technique has changed the immediate and longterm results of LVR, especially in borderline cases in which the patient is in the final stage of drug-resistant CHF and heart transplantation appears to be the only safe solution. In such cases, only a precise analysis of the very limited remaining contractile myocardium on the anterior, septal, and posterior walls will show whether "viable" contractile cavity can be rebuilt.

For surgical treatment of ischemic CHF, in addition to coronary revascularization, mitral valve repair and the correction of ventricular arrhythmias where appropriate, the use of LVR by EVCPP may further improve cardiac performance for two key reasons. First, LVR suppresses and excludes the asynergic area of the left ventricular wall, the area responsible for left ventricular remodeling. The 

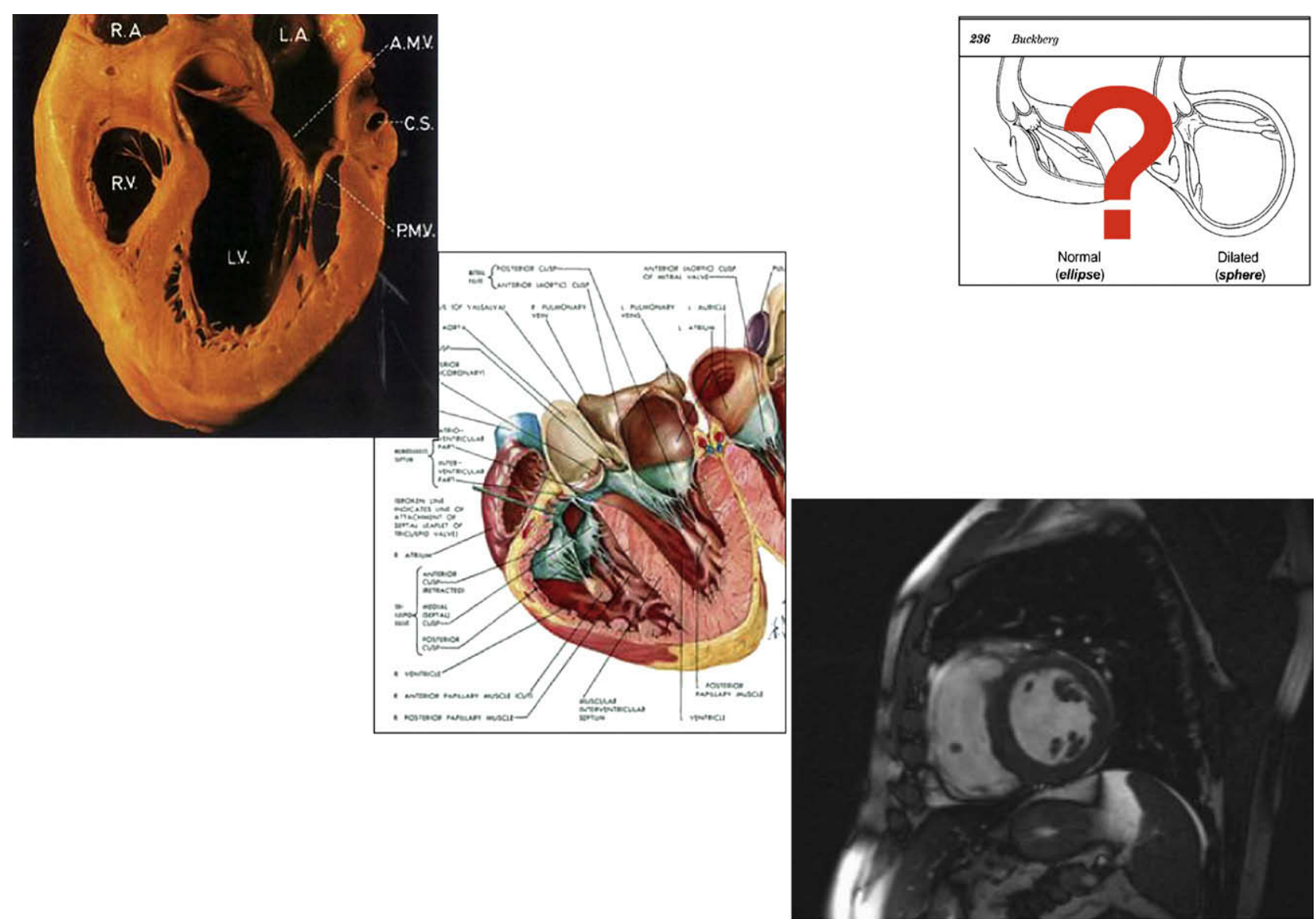

MRI short axis

FIGURE 3. Autopsy left ventricular transection, anatomy atlas, and magnetic resonance imaging short-axis view confirm lack of insertion of papillary muscle on septum.

importance of this asynergic area in left ventricular remodeling is clearly demonstrated by postoperative MRI analysis, in which the LGE percentage is seen to decrease from $50 \%$ to less than $30 \%$ with removal of this tissue (Figure 7). Scar exclusion by small circular patch anchored on contractile myocardium restores the curvature of the left ventricular wall and suppresses the deleterious systolic eccentric motion of viable myocardium remote from the scarred area. This prompts a return to a systolic concentric contraction, as demonstrated by a dynamic analysis of the left ventricular wall and return to pressure-volume loop morphology seen before distortion. ${ }^{21}$ Second, LVR maintains the physiologically appropriate diastolic volume, preventing any immediate or delayed effects of excessive volume reduction. It should be emphasized that LVR is to be conducted on the arrested heart. Not only does arresting the heart facilitate concomitant procedures, such as mitral valve repair and the correction of ventricular arrhythmias, it facilitates sizing of the diastolic volume and subtotal endocardectomy, both integral aspects of LVR surgery.

In a series of patients from our institution, each of whom had a very depressed IFV before undergoing DVBS, in-hos- pital mortality decreased from $15 \%$ to $8 \%$. The secondary recurrence of remodeling also decreased from $25 \%$ to less than $10 \%$. Furthermore, a comparison of in-hospital mortalities and 5-year survivals between our earlier experience and our more contemporary experience shows that results have improved with time (Table 1).

\section{MRI AND POSTRECONSTRUCTION FOLLOW-UP}

LVR by EVCPP with preservation of diastolic volumes improves both systolic and diastolic function. For decades, many cardiologists were of the opinion that left ventricular aneurysm surgery did not result in improved LVEF. ${ }^{22}$ Indeed, aneurysm surgery was historically limited to the resection of the scarred external area, followed by a linear suture. With this technique, akinetic septum was left inside the left ventricular cavity. Since the use of circular reorganization, external for $\mathrm{Sosa}^{23}$ and endoventricular LVR, however, the improvement in systolic function has been clearly demonstrated. All published data from the RESTORE group, as well as published data from others have indicated an increase in postoperative ejection fraction in the range of $7 \%$ to $15 \%$ after LVR reconstruction. ${ }^{24-26}$ It would be of great interest 

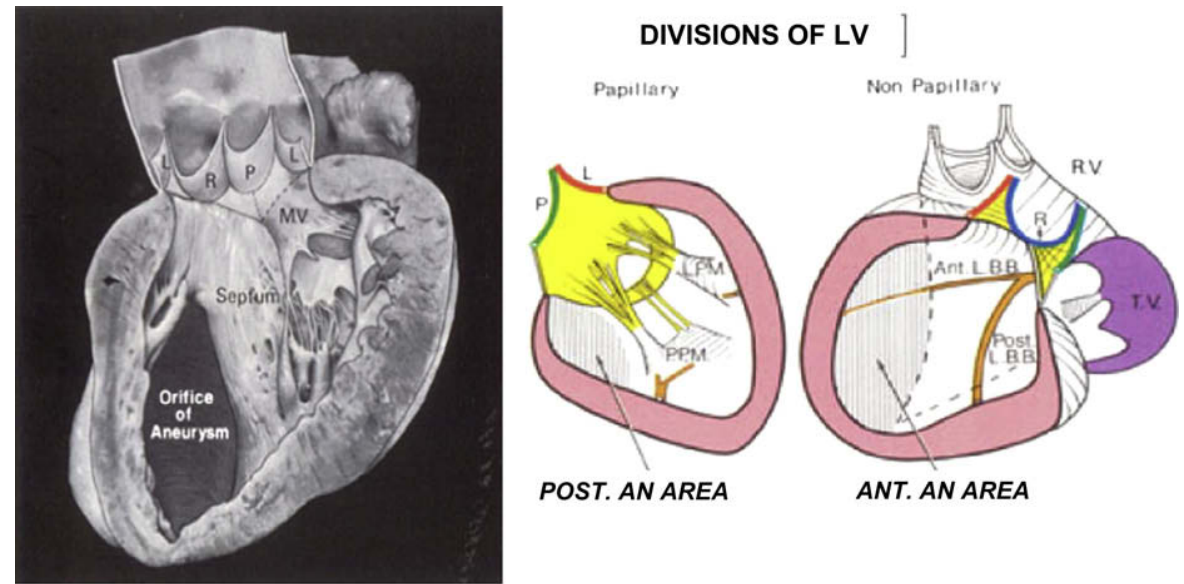

\section{Mc Alpine 1975}

FIGURE 4. From: McAlpine WA, editor. Heart and coronary arteries: an anatomical atlas for clinic diagnosis, radiological investigation, and surgical treatment. New York: Springer-Verlag; 1975. p. 34.

for these postoperative results to be assessed by MRI months and years after surgery. We have used MRI at our institution for such comparisons and gained promising results. In a series of more than 100 consecutive patients with IFV operated on from 2002 to 2006 , we were able to precisely document improvements in ejection fraction, EDVI, and ESVI with MRI early and 1 year postoperatively (Table 2 ).

\section{Diastolic Function}

Currently, the published literature supports LVR as a surgical option to improve systolic function and quality of life for select patients with ischemic cardiomyopathy. Most patients who undergo LVR have end-stage heart failure with a restrictive pattern and increased pulmonary pressure before surgery. Recently, Menicanti and colleagues ${ }^{27}$ suggested

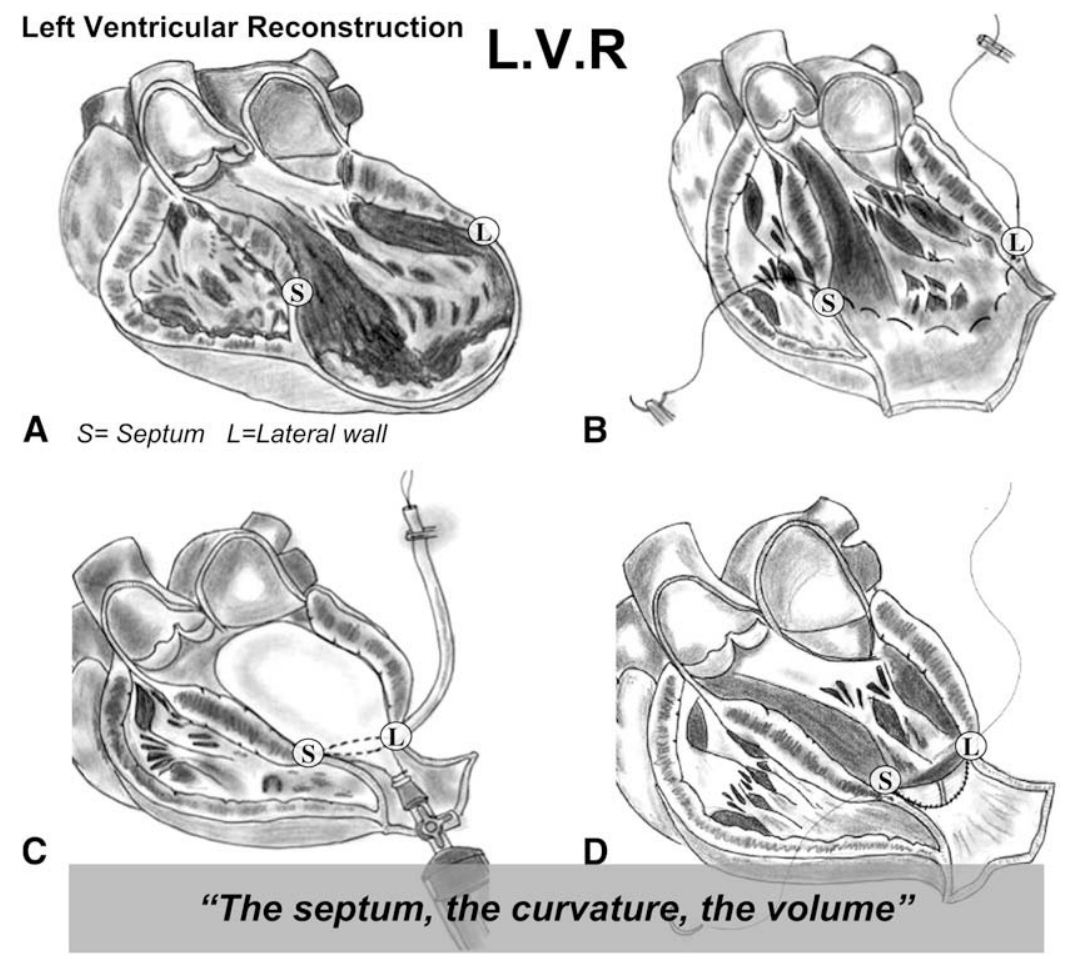

FIGURE 5. Left ventricular reconstruction. A, Anteroseptoapical aneurysm with mural thrombi. Dilatation also affects unscarred myocardium on septum $(S)$ and lateral wall $(L)$. B, Continuous purse-string suture at limit between fibrous and normal myocardium (Fontan trick) C, Suture is tied on rubber balloon inflated to $50 \mathrm{~mL} / \mathrm{m}^{2}$ body surface area (normal diastolic volume). Shortening of SL length illustrates reorganization of curvature. D, Dacron polyester fabric patch anchored on suture. Right ventricular apex projects beyond new left ventricular apex. 


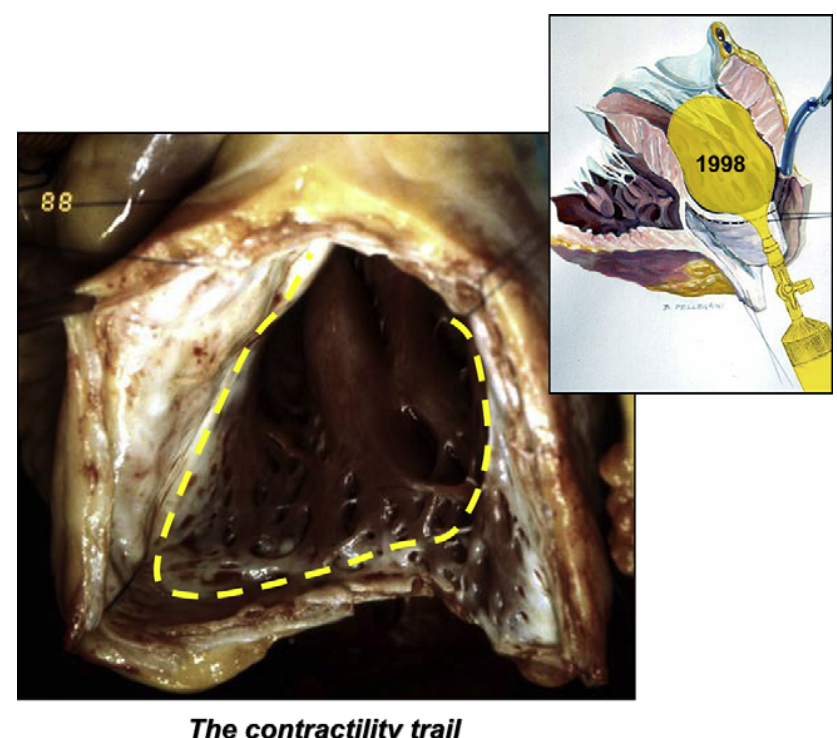

FIGURE 6. Endoventricular purse-string suture (Fontan trick) positioned at limit between contractile and scarred myocardium and tied on rubber balloon inflated at theoretic diastolic capacity of left ventricle.

that patients with severe preoperative diastolic dysfunction may have worse outcome after LVR.

An increasing number of patients undergo LVR in association with a surgical procedure on the mitral valve (annuloplasty, edge-to-edge technique). ${ }^{28}$ Such concomitant procedures completely change the aspect of transmitral flow and modify the myocardial velocities at the annular level of the mitral valve. The standard echocardiographic criteria are therefore not applicable.

Potentially more appropriate for such analyses, as done at our institution, is to assess the pressure-volume loop and the tendency of the left part of this loop toward lower values, in addition to assessing the increase in peak filling rate and the shortening of peak filling rate times. ${ }^{29}$ Notably, these assessments are not possible in all cases. Another alternative that has been suggested is to assess the end-diastolic and endsystolic pressure-volume relationship. ${ }^{30}$ The results from these studies are somewhat difficult to interpret, however, because certain measurements were made while the patients were still receiving inotropic agents. Tulner and colleagues ${ }^{31}$ reported increases in diastolic chamber stiffness and in end-diastolic pressure immediately after the procedure. But the same authors reported significant reductions in pulmonary arterial pressures 6 months after LVR, suggesting an immediate compliance problem intraoperatively.

Left atrial enlargement has been proposed as a marker of left ventricular diastolic function. ${ }^{32}$ The normal values of left atrial volume index are considered to be $22 \pm 6 \mathrm{~mL} /$ $\mathrm{m}^{2}$ for all ages. In our center, the assessment of the left atrial volume, indexed by MRI with the length-surface method for 31 consecutive patients with ischemic CHF referred for LVR (26 LVR alone, 5 LVR with mitral valve repair), showed a decrease in left atrial volume index from $39.8 \pm 22.3$ $\mathrm{mL} / \mathrm{m}^{2}$ before the operation to $27.4 \pm 14.7 \mathrm{~mL} / \mathrm{m}^{2} 1$ month

\section{Case $\mathrm{N}^{\circ} 1079 \mathrm{CHF}$ III $+\ldots 4$ years after successfull LAD stenting}
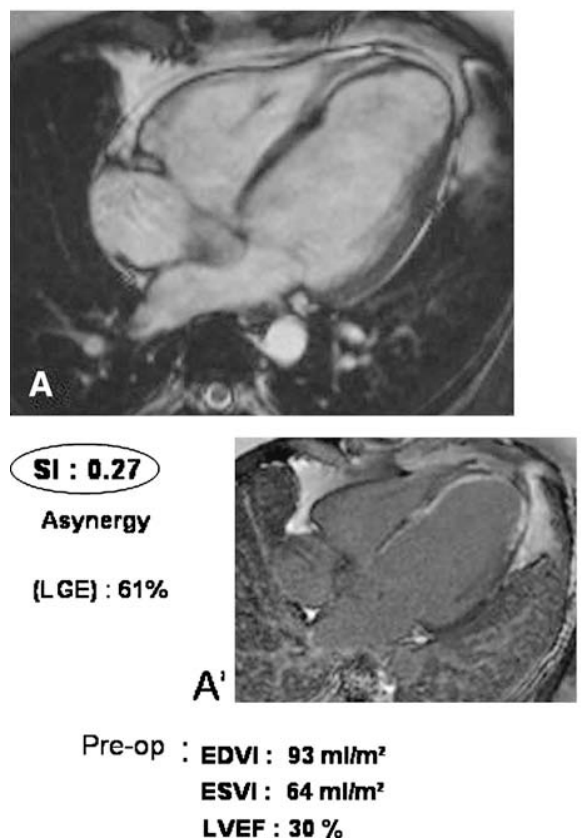
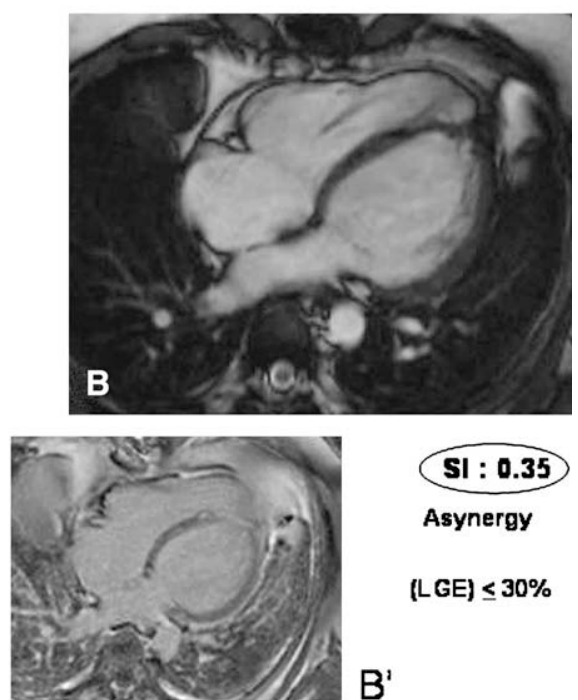

Asynergy

(LGE) $\leq 30 \%$
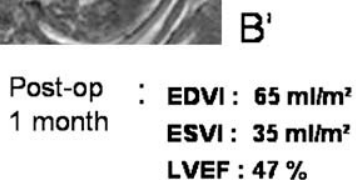

FIGURE 7. Case of patient 4 years after successful left anterior descending stenting. A, Preoperative 4-chamber view. A', Mural scar (late gadolinium enhancement, $L G E$ ) on same view, B, Postoperative 4-chamber view. Right ventricle projects beyond new left ventricular apex. $\mathrm{B}^{\prime}$, Residual scar is below $30 \%$. 
TABLE 1. Results of left ventricular reconstruction in two series

\begin{tabular}{|c|c|c|c|c|c|c|c|}
\hline & \multirow[b]{2}{*}{ Total } & \multirow[b]{2}{*}{ In-hospital death } & \multirow[b]{2}{*}{ Follow-up } & \multicolumn{2}{|c|}{ LVEF (mean \%) } & \multirow[b]{2}{*}{ Late death } & \multirow[b]{2}{*}{ 5-y survival } \\
\hline & & & & Before & After & & \\
\hline $1991-1996^{*}$ & 245 & $20(8.1 \%)$ & $207 / 225(92 \%)$ & $35 \%$ & $48 \%$ & $27(13 \%)$ & $82 \% \dagger$ \\
\hline 1998-2003 & 252 & $12(4.8 \%)$ & $235 / 240(98 \%)$ & $35 \%$ & $50 \%$ & $13(5.5 \%)$ & $85 \%$ \\
\hline
\end{tabular}

LVEF, Left ventricular ejection fraction. ${ }^{*}$ Without diastolic balloon sizing. $\dagger$ Hospital death not included.

after the intervention $(P=.009)$. Eighty-two percent of the patients had diminished left atrial volume index values after surgery showing improved diastolic function (Table 3).

\section{Repair of Ischemic Mitral Regurgitation}

Mitral valve repair is performed by the atrial approach before LVR. The reduction of the posterior mitral annular diameter from more than $40 \mathrm{~mm}$ to 25 to $30 \mathrm{~mm}$ appears stable years after surgery, contrary to the Cleveland clinic series, which suggested that ischemic mitral regurgitation is a progressive ventricular disease unless reconstructed. ${ }^{33}$

The improvement of contractility is not related to shape. Although Buckberg and associates ${ }^{34}$ have suggested that a spherical cavity is less contractile than an elliptic one, the dogma of elliptic shape was established without convincing physical or physiologic data. Proponents of this idea suggest that progressive postoperative impairment correlates with a poor sphericity index (SI). ${ }^{35}$ With a true measurement of SI (calculated by the ratio between systolic and diastolic volumes of a sphere with the same long diameter as the left ventricle and not by the ratio between longitudinal and transversal diameters checked by echocardiography), it appears that before repair, the great majority of large anteroseptoapical asynergies are more elliptic than spherical and that excellent immediate and delayed results in terms of contractility and systolic and diastolic functions are associated with an increase in the postoperative SI value.

A comparison of LVEF, ESVI, and SI index values at 1 month and 1 year postoperatively were carried out in 40 consecutive cases of anteroseptoapical aneurysm. It appears that there is no relationship between quality of result, indicated by a progressive increase of LVEF, and changes in ESVI

TABLE 2. Magnetic resonance imaging-documented results in 104 patients with ischemic failing ventricle, May 2002 through August 2006

\begin{tabular}{lccc}
\hline & Preoperative & 1st Month & 1st Year \\
\hline Ejection fraction (\%) & $26 \pm 5$ & $40 \pm 7^{*}$ & $45 \pm 8 \dagger$ \\
$\begin{array}{l}\text { End-diastolic volume } \\
\text { index }\left(\mathrm{mL} / \mathrm{m}^{2}\right)\end{array}$ & $125 \pm 37$ & $83 \pm 23^{*}$ & $81 \pm 20$ \\
$\begin{array}{c}\text { End-systolic volume } \\
\text { index }\left(\mathrm{mL} / \mathrm{m}^{2}\right)\end{array}$ & $93 \pm 29$ & $51 \pm 18^{*}$ & $46 \pm 17 \ddagger$ \\
\hline
\end{tabular}

All patients with class III or IV congestive heart failure, left ventricular ejection fraction less than $30 \%$ (mean $26 \% \pm 5 \%$ ), end-systolic volume index greater than $60 \mathrm{~mL} /$ $\mathrm{m}^{2}$ (mean $93 \pm 28 \mathrm{~mL} / \mathrm{m}^{2}$ ), scar (by late gadolinium enhancement) of $35 \%$ to $69 \%$ (mean $49.5 \%$ ). Follow-up $100 \%$ complete, with 9 deaths and 10 patients without improvement. $* P=.0001$ vs pre-op. $\dagger P=.0001 . \ddagger P=.004$ vs 1 month post-op. and SI, which can sometimes decrease and sometimes increase.

The goal of efficient LVR is to reestablish the systolic concentric contraction of the whole left ventricular wall, connecting the contractile myocardium by the circular suture positioned on the "contractility trail," made to measure in each case. The postoperative improvement must be assessed not only in the immediate postoperative period but also after months and years. Contrary to the commonly accepted opinion of secondary failure, ${ }^{36}$ in more than $80 \%$ of cases of rebuilt left ventricles for IFV with very poor preoperative left ventricular performance, progressive, statistically significant improvement has been observed, confirming the reversion of left ventricular remodeling. ${ }^{37}$

\section{CONCLUSIONS}

MRI of IFV allows cardiologists and cardiac surgeons to refresh their knowledge of the real anatomy of normal and the diseased ischemic left ventricle, thus avoiding irrational inventions of mechanisms and recourse to questionable techniques. LGE cartography allows verification of the feasibility of LVR, suggests how it must be carried out, and helps to set the limits of indications.

Because endocardectomy is often helpful to localize the "contractility trail," and above all because DVBS is key in effective immediate and long-term results, LVR cannot be correctly accomplished on a beating heart.

For IFV, LVR by EVCPP excluding asynergic areas restores efficient systolic concentric contraction of the left ventricular wall with preservation of physiologically appropriate volumes, improving both systolic and diastolic functions. The deleterious effects of left ventricular remodeling, even in apparently hopeless situations, may be reversible.

TABLE 3. Results of left ventricular reconstruction in 31 consecutive patients with left atrial volume index measurements

\begin{tabular}{lccc}
\hline & Preoperative & Postoperative & $\boldsymbol{P}$ value \\
\hline $\begin{array}{l}\text { End-diastolic volume } \\
\text { index }\left(\mathrm{mL} / \mathrm{m}^{2}\right)\end{array}$ & $98.4 \pm 33.5$ & $65.4 \pm 19.3$ & $<.001$ \\
$\begin{array}{l}\text { End-systolic volume } \\
\quad \text { index }\left(\mathrm{mL} / \mathrm{m}^{2}\right)\end{array}$ & $63 \pm 30$ & $35.8 \pm 14.2$ & $<.001$ \\
$\begin{array}{l}\text { Left atrial volume index } \\
\left(\mathrm{mL} / \mathrm{m}^{2}\right)\end{array}$ & $39.8 \pm 22.3$ & $27.4 \pm 14.7$ & $<.05$ \\
\hline
\end{tabular}

Left ventricular ejection fraction less than 30\% (mean 26\%). Left ventricular reconstruction alone in 26 cases and with mitral valve repair in 5 cases. 
We thank John Bee and Scott McClure, MD, for their English language assistance during the preparation and acceptance of this article.

\section{References}

1. Kirklin JW. In: McAlpine WA, ed. Heart and coronary arteries: an anatomical atlas for clinic diagnosis, radiological investigation, and surgical treatment. New York: Springer-Verlag; 1975.

2. Pennell DJ, Sechtem UP, Higgins CB, Manning WJ, Pohost GM, Rademakers FE, et al. Clinical indications for cardiovascular magnetic resonance (CMR): Consensus Panel report. Eur Heart J. 2004;25:1940-65.

3. Mahrholdt H, Wagner A, Judd RM, Sechtem U. Assessment of myocardial viability by cardiovascular magnetic resonance imaging. Eur Heart J. 2002;23:612-9.

4. Bellenger NG, Burgess MI, Ray SG, Lahiri A, Coats AJ, Cleland JG, et al. Comparison of left ventricular ejection fraction and volumes in heart failure by echocardiography, radionuclide, ventriculography and cardiovascular magnetic resonance: are they interchangeable? Eur Heart J. 2000;21:1295-7.

5. Klein MD, Herman MV, Gorlin R. A hemodynamic study of left ventricular aneurysm. Circulation. 1967;35:614-30.

6. McKay RG, Pfeffer MA, Pasternak RC, Markis JE, Come PC, Nakao S, et al. Left ventricular remodeling after myocardial infarction: a corollary to infarct expansion. Circulation. 1986;74:693-702.

7. Ito H, Maruyama A, Iwakura K, Takiuchi S, Masuyama T, Hori M, et al. Clinical implications of the "no reflow" phenomenon. A predictor of complications and left ventricular remodeling in reperfused anterior wall myocardial infarction. Circulation. 1996;93:223-8.

8. Reffelmann T, Hale SL, Dow JS, Kloner RA. No-reflow phenomenon persists long-term after ischemia/reperfusion in the rat and predicts infarct expansion. Circulation. 2003;108:2911-7.

9. Yellon DM, Hausenloy DJ. Myocardial reperfusion injury. N Engl J Med. 2007; 357:1121-35.

10. Mannaerts HF, van der Heide JA, Kamp O, Stoel MG, Twisk J, Visser CA. Early identification of left ventricular remodeling after myocardial infarction assessed by transthoracic 3D echocardiography. Eur Heart J. 2004;25:680-7.

11. White HD, Norris RM, Brown MA, Brandt PW, Whitlock RM, Wild CJ. Left ventricular end-systolic volume as the major determinant of survival after recovery from myocardial infarction. Circulation. 1987;76:44-51.

12. Bogaert J, Maes A, Van de Werf F, Bosmans H, Herregods MC, Nuyts J, et al. Functional recovery of subepicardial myocardial tissue in transmural myocardial infarction after successful reperfusion: an important contribution to the improvement of regional and global left ventricular function. Circulation. 1999;99:36-43.

13. Sheehan FH, Bolson EL, Dodge HT, Mathey DG, Schofer J, Woo HW. Advantages and applications of the centerline method for characterizing regional ventricular function. Circulation. 1986;74:293-305.

14. Fieno DS, Kim RJ, Chen EL, Lomasney JW, Klocke FJ, Judd RM. Contrast-enhanced magnetic resonance imaging of myocardium at risk: distinction between reversible and irreversible injury throughout infarct healing. J Am Coll Cardiol. 2000;36:1985-91.

15. Buckberg G, Menicanti L, De Oliveira S, Isomura T, RESTORE team. Restoring papillary muscle dimensions during restoration in dilated hearts. Interact Cardiovasc Thorac Surg. 2005;4:475-7.

16. McAlpine WA, ed. Heart and coronary arteries: an anatomical atlas for clinic diagnosis, radiological investigation, and surgical treatment. New York: SpringerVerlag; 1975. p. 34.

17. Dor V, Kreitmann P, Jourdan J, Acar C, Saab M, Coste P. Interest of “ "physiological closure"' (circumferential plasty on contractile areas) of left ventricle after resection and endocardectomy for aneurysm of akinetic zone: comparison with classical technique about a series of 209 left ventricular resections [abstract]. J Cardiovasc Surg. 1985;26:73.
18. Dor V, Saab M, Coste P, Kornaszewska M, Montiglio F. Left ventricular aneurysm: a new surgical approach. Thorac Cardiovasc Surg. 1989;37:11-9.

19. Dor V, Sabatier M, Montiglio F, Coste P, Di Donato M. Endoventricular patch reconstruction in large ischemic wall-motion abnormalities. J Card Surg. 1999; $14: 46-52$.

20. Dor V. The endoventricular circular patch plasty ("Dor procedure") in ischemic akinetic dilated ventricles. Heart Fail Rev. 2001;6:187-93.

21. Di Donato M, Sabatier M, Toso A, Barietta G, Baroni M, Dor V, et al. Regional myocardial performance of non-ischaemic zones remote from anterior wall left ventricular aneurysm. Effects of aneurysmectomy. Eur Heart J. 1995;16: 1285-92.

22. Froehlich RT, Falsetti HL, Doty DB, Marcus ML. Prospective study of surgery for left ventricular aneurysm. Am J Cardiol. 1980;45:923-31.

23. Sosa E, Jatene A, Kaeriyama JV, Scanavacca M, Marcial MB, Bellotti G, et al. Recurrent ventricular tachycardia associated with postinfarction aneurysm. Results of left ventricular construction. J Thorac Cardiovasc Surg. 1992;103:855-60.

24. Athanasuleas CL, Buckberg GD, Stanley AW, Siler W, Dor V, DiDonato M, et al. Surgical ventricular restoration: the RESTORE Group experience. Heart Fail Rev. 2004;9:287-97.

25. Sartipy U, Albage A, Lindblom D. The Dor procedure for left ventricular reconstruction. Ten-year clinical experience. Eur J Cardiothorac Surg. 2005;27: 1005-10.

26. Calafiore AM, Mauro MD, Di Giammarco G, Gallina S, Iaco AL, Contini M, et al. Septal reshaping for exclusion of anteroseptal dyskinetic or akinetic areas. Ann Thorac Surg. 2004; 77:2115-21

27. Menicanti L, Castelvecchio S, Ranucci M, Frigiola A, Santambrogio C, de Vincentiis C, et al. Surgical therapy for ischemic heart failure: single-center experience with surgical anterior ventricular restoration. J Thorac Cardiovasc Surg. 2007; 134:433-41.

28. Maisano F, Torracca L, Oppizzi M, Stefano PL, D’Addario G, La Canna G, et al. The edge-to-edge technique: a simplified method to correct mitral insufficiency. Eur J Cardiothorac Surg. 1998;13:240-5.

29. Dor V, Di Donato M, Sabatier M, Montiglio F, Civaia F, RESTORE Group. Left ventricular reconstruction by endoventricular circular patch plasty repair: a 17year experience. Semin Thorac Cardiovasc Surg. 2001;13:435-47.

30. Burkhoff D, Wechsler AS. Surgical ventricular remodeling: a balancing act on systolic and diastolic properties. J Thorac Cardiovasc Surg. 2006;132:459-63.

31. Tulner SA, Bax JJ, Bleeker GB, Steendijk P, Klautz RJ, Holman ER, et al. Beneficial hemodynamic and clinical effects of surgical ventricular restoration in patients with ischemic dilated cardiomyopathy. Ann Thorac Surg. 2006;82:1721-7.

32. Abhayaratna WP, Seward JB, Appleton CP, Douglas Ps, OH JK, Tajik AJ, et al. Left atrial size: physiologic determinants and clinical applications. J Am Coll Cardiol. 200620;47:2357-63.

33. McGee EC, Gillinov AM, Blackstone EH, Rajeswaran J, Cohen G, Najam F, et al. Recurrent mitral regurgitation after annuloplasty for functional ischemic mitral regurgitation. J Thorac Cardiovasc Surg. 2004;128:916-24.

34. Buckberg GD, Coghlan HC, Torrent-Guasp F. The structure and function of the helical heart and its buttress wrapping. VI. Geometric concepts of heart failure and use for structural correction. Semin Thorac Cardiovasc Surg. 2001;13: 386-401.

35. Di Donato M, Dabic P, Castelvecchio S, Santambrogio C, Brankovic J, Collarini L, et al. Left ventricular geometry in normal and post-anterior myocardial infarction patients: sphericity index and 'new' conicity index comparisons. Eur J Cardiothorac Surg. 2006;29(Suppl. 1):S225-30.

36. Ratcliffe MB, Guy TS. The effect of preoperative diastolic dysfunction on outcome after surgical ventricular remodeling. J Thorac Cardiovasc Surg. 2007; 134:280-3.

37. Dor V, Sabatier M, Montiglio F, Civaia F, DiDonato M. Endoventricular patch reconstruction of ischemic failing ventricle. A single center with 20 years experience. Advantages of magnetic resonance imaging assessment. Heart Fail Rev. 2004;9:269-86. 